\title{
Growth Season Photochemical Pollution over the UK Based on 1990-2006 Ozone Data
}

\author{
Brunislav Matasović, ${ }^{a, *}$ Leo Klasinc, ${ }^{a}$ and Tomislav Cvitaš ${ }^{b}$ \\ ${ }^{a}$ Division of Physical Chemistry, "Rudjer Boskovic" Institute, HR-10002 Zagreb, Bijenička c. 54, Croatia \\ ${ }^{\mathrm{b}}$ Chemistry Department, Faculty of Science, University of Zagreb, HR-10002 Zagreb, Horvatovac 102a, Croatia
}

RECEIVED SEPTEMBER 25, 2012; REVISED DECEMBER 11, 2012; ACCEPTED JANUARY 7, 2013

\begin{abstract}
Ozone data from 13 rural and 11 urban sites for the growth season (April through September) during 1990-2006 have been analysed on the basis of recently introduced photochemical pollution indicators. The indicators predict that urban sites are prone to photochemical pollution, although compared to some rural sites, the urban sites have lower average ozone concentrations and showed lower values of time for which hourly average ozone concentration is above a threshold value. Interestingly, the frequency distribution of ozone concentrations, especially the frequency of very low (close to zero) concentrations, correlates well with the average ozone volume fraction during the growth period. The present analysis shows that photochemical pollution in the UK is less severe compared with photochemical pollution in central Europe and the Mediterranean region (Italy, Croatia, Slovenia).(doi: 10.5562/cca2177)
\end{abstract}

Keywords: photochemical pollution, pollution indicators, ambient ozone, ozone monitoring, growth season, average hourly ozone data

\section{INTRODUCTION}

Owing to its oxidizing capacity, elevated ozone concentrations in the planetary boundary layer are harmful to most life forms. ${ }^{1}$ Earth's atmosphere contains naturally occurring ozone transported from the stratosphere and ozone created in the troposphere by electric discharges that can break oxygen molecules into atoms that form ozone, but most ozone comes from human activities that release NO as the primary pollutant which is, than, rapidly oxidized to brown nitrogen dioxide $\left(\mathrm{NO}_{2}\right)$. Photolysis by sunlight of $\mathrm{NO}_{2}$ to oxygen atoms is the main source of ozone formation in the troposphere. During night, in the absence of sunlight, $\mathrm{NO}_{2}$ is further oxidized to $\mathrm{NO}_{3} \cdot$ and finally to $\mathrm{N}_{2} \mathrm{O}_{5}$ and $\mathrm{HNO}_{3}$. Naturally occurring corresponding $\mathrm{NO}_{\mathrm{x}}$ concentrations in the atmosphere are very low (its sources being wildfires and lightning) and considerably increased values of $\mathrm{NO}_{\mathrm{x}}$ can invariably be associated with human activities (energy generation, chemical industries, transport and combustion processes). The increase in atmospheric ozone volume fractions observed worldwide nowadays is generally considered as pollution. It is predicted that a further rise in tropospheric ozone concentrations will occur in the future ${ }^{2}$ affecting the crops. ${ }^{3}$

Ozone can be easily and reliably monitored, and based on the average hourly ozone volume fractions at many locations over long periods of time, a number of indices, directives and air quality standards and limits have been put forward in order to quantify the air quality affecting humans, vegetation and materials. ${ }^{4,5}$ Long-term ozone monitoring results at various European locations ${ }^{6}$ have shown that along with a high daily value of ozone volume fractions, the extent of the diurnal variation expressed as the ratio of maximum to minimum ozone volume fractions gives a much better insight into the atmospheric condition known as photochemical pollution (PP). The recent analysis of more than 14 years of whole-year ozone data from 18 monitoring stations in the UK by Jenkin ${ }^{7}$ revealed interesting results on trends in the ozone concentration distribution as well as on local, regional and global influences. This analysis showed that as a rule, the annual mean $\mathrm{O}_{3}$ concentration was higher in rural sites than in urban sites. It identified $\mathrm{NO}_{\mathrm{x}}$ concentrations as the main cause and state that ozone concentrations over the UK were affected by ozone transported into the UK from the Atlantic Ocean as well as by the formation of additional ozone formed photochemically from volatile organic compounds and $\mathrm{NO}_{\mathrm{x}}$ emitted over north-western Europe and transported to the UK. However, in terms of air quality, this longterm analysis does not show the expected differentiation between urban and rural locations in the UK nor provide

\footnotetext{
$\dagger$ This article belongs to the Special Issue devoted to the $85^{\text {th }}$ anniversary of Croatica Chemica Acta.

* Author to whom correspondence should be addressed. (E-mail: bmatasov@irb.hr)
} 
Table 1. Geographical coordinates of monitoring sites

\begin{tabular}{|c|c|c|c|c|}
\hline Monitoring station & Station abbrev. & N Latitude & Longitude & Altitude \\
\hline Aston Hill & $\mathrm{AH}$ & $52.504^{\circ}$ & $3.033^{\circ} \mathrm{W}$ & $370 \mathrm{~m}$ \\
\hline Belfast Centre $^{(a)}$ & $\mathrm{BE}$ & $54.616^{\circ}$ & $5.903^{\circ} \mathrm{W}$ & $8 \mathrm{~m}$ \\
\hline Birmingham Centre $^{(a)}$ & BI & $52.479^{\circ}$ & $1.906^{\circ} \mathrm{W}$ & $145 \mathrm{~m}$ \\
\hline Bottesford & $\mathrm{BO}$ & $52.929^{\circ}$ & $0.815^{\circ} \mathrm{W}$ & $32 \mathrm{~m}$ \\
\hline Bush Estate & BU & $55.859^{\circ}$ & $3.206^{\circ} \mathrm{W}$ & $180 \mathrm{~m}$ \\
\hline Cardiff Centre $^{(a)}$ & $\mathrm{CA}$ & $51.481^{\circ}$ & $3.174^{\circ} \mathrm{W}$ & $20 \mathrm{~m}$ \\
\hline Eskdalemuir & ES & $55.313^{\circ}$ & $3.204^{\circ} \mathrm{W}$ & $269 \mathrm{~m}$ \\
\hline Glazebury & GL & $53.459^{\circ}$ & $2.466^{\circ} \mathrm{W}$ & $21 \mathrm{~m}$ \\
\hline Harwell & HW & $51.573^{\circ}$ & $1.316^{\circ} \mathrm{W}$ & $137 \mathrm{~m}$ \\
\hline High Muffles & HM & $54.334^{\circ}$ & $0.807^{\circ} \mathrm{W}$ & $267 \mathrm{~m}$ \\
\hline Ladybower & LB & $53.399^{\circ}$ & $1.753^{\circ} \mathrm{W}$ & $420 \mathrm{~m}$ \\
\hline Leeds Centre $^{(a)}$ & LE & $53.804^{\circ}$ & $1.546^{\circ} \mathrm{W}$ & $71 \mathrm{~m}$ \\
\hline Liverpool Centre $^{(\mathrm{a})}$ & LI & $53.408^{\circ}$ & $2.981^{\circ} \mathrm{W}$ & $20 \mathrm{~m}$ \\
\hline London Bloomsbury ${ }^{(a)}$ & LO & $51.521^{\circ}$ & $0.124^{\circ} \mathrm{W}$ & $39 \mathrm{~m}$ \\
\hline London Hillingdon $^{\text {(a) }}$ & & $51.496^{\circ}$ & $0.461^{\circ} \mathrm{W}$ & $31 \mathrm{~m}$ \\
\hline London Marylebone $^{(a)}$ & & $51.522^{\circ}$ & $0.155^{\circ} \mathrm{W}$ & $36 \mathrm{~m}$ \\
\hline London Teddington $^{(\mathrm{a})}$ & & $51.421^{\circ}$ & $0.340^{\circ} \mathrm{W}$ & $13 \mathrm{~m}$ \\
\hline Lough Navar & $\mathrm{LN}$ & $54.443^{\circ}$ & $7.872^{\circ} \mathrm{W}$ & $130 \mathrm{~m}$ \\
\hline Lullington Heath & LH & $50.793^{\circ}$ & $0.182^{\circ} \mathrm{E}$ & $120 \mathrm{~m}$ \\
\hline Manchester Piccadilly $^{(\mathrm{a})}$ & MA & $53.481^{\circ}$ & $2.238^{\circ} \mathrm{W}$ & $45 \mathrm{~m}$ \\
\hline Reading $^{(a)}$ & RE & $51.454^{\circ}$ & $0.955^{\circ} \mathrm{W}$ & $44 \mathrm{~m}$ \\
\hline Sibton & SI & $52.294^{\circ}$ & $0.464^{\circ} \mathrm{E}$ & $46 \mathrm{~m}$ \\
\hline Strath Vaich & SV & $57.734^{\circ}$ & $4.775^{\circ} \mathrm{W}$ & $270 \mathrm{~m}$ \\
\hline Yarner Wood & YW & $50.596^{\circ}$ & $3.715^{\circ} \mathrm{W}$ & $119 \mathrm{~m}$ \\
\hline
\end{tabular}

(a) urban station

any ranking among the different sites as was found in central European, Mediterranean (Italy, Slovenia, Croatia), and even some subtropical stations.

In spite of ozone being the most abundant substance in the hazardous atmospheric condition known as photosmog, there are numerous components in this reactive brew that cause adverse effects. Since ozone reaction products with VOCs - aldehydes, peroxides, radicals, peroxy acyl nitrates, quinonoids, secondary organic aerosols ${ }^{8}$ - represent very potent pollution components, new pollution indicators have been devised. In this study, we describe the PP indicators that take into account corrections for the amount of daylight ozone production and the number of hours the hourly average exceeds a chosen limiting value over a given period (here, the vegetation growth season from April 1 till September 30). We then apply these indicators on the expanded set of UK stations ${ }^{7}$ during the growth season to confirm their value in air quality assessment.

\section{METHODS}

All the data used were obtained by the UK ozone monitoring Automatic Urban and Rural Network (AURN) set up by the UK Department for Environment, Food and Rural Affairs (DEFRA). The locations of all the monitoring sites are given in Table 1 and shown on the map in Fig. 1. Ambient concentrations of ozone can be obtained from the National Air Quality Information Archive (http://uk-air.defra.gov.uk/). All the data, originally shown as mass concentrations in $\mu \mathrm{g} \mathrm{m}^{-3}$, were converted to volume fractions in $\mathrm{ppb}$.

The calculation method has been described previously $^{6}$ and was developed by analysing 10 years of ozone data from 12 European Monitoring and Evaluation of air Pollutants program (EMEP) stations over Europe. Originally, two indicators were proposed,

$$
P_{1}=R M / A
$$

and

$$
P_{2}=R\left(1+168 t_{\mathrm{exc}} / N\right)
$$

where $R$ is the average of the daily maximum-tominimum ratios, $M$ is the seasonal average of the daily maximum values, $A$ is the average of all the seasonal data, $t_{\mathrm{exc}}$ is the number of hours in which the limit of 80 


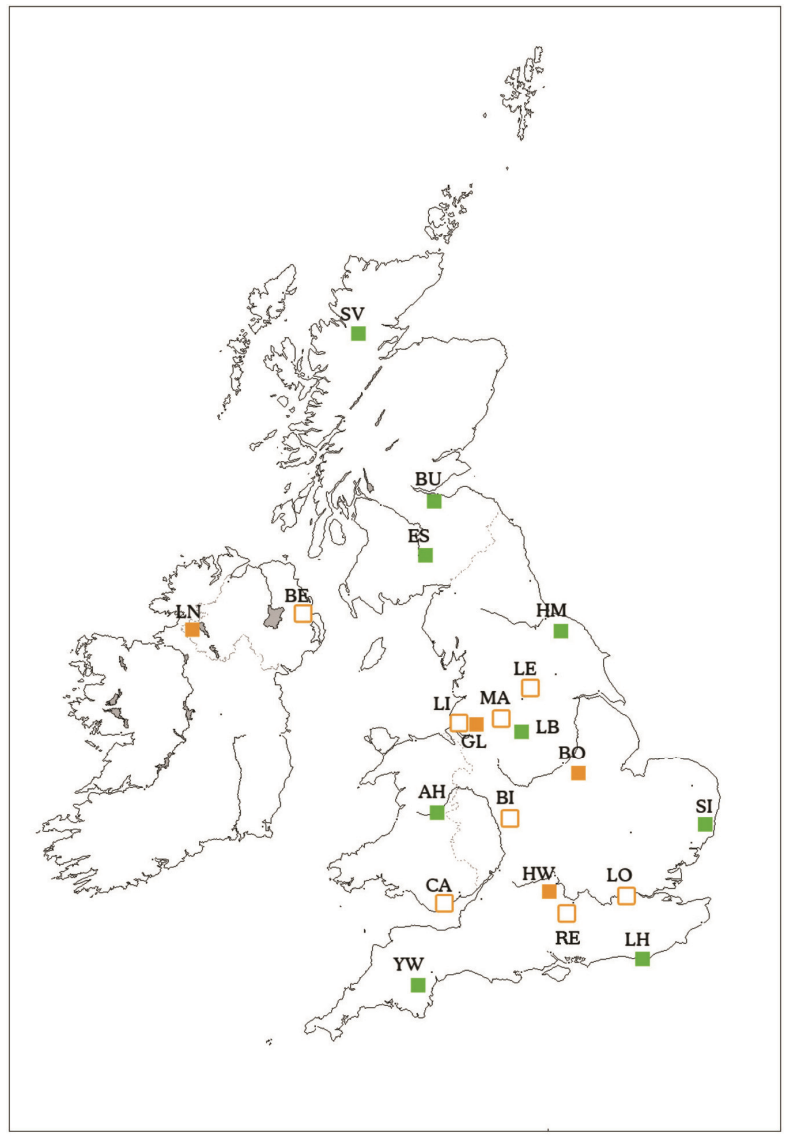

Figure 1. Map of the UK showing the locations of the monitoring sites. The names of the stations and their geographical coordinates are given in Table 1. Green squares represent low photochemical pollution sites, orange those of medium pollution. Solid squares represent the rural sites, blank squares represent the urban sites. Station abbreviations are shown in Table 1.

ppb was exceeded ("excess time") and $N$ is the total number of hourly averages of ozone volume fractions measured.

As we can see from the above equations, both of these indicators are based on the daily maximum-tominimum ratio $R$ of the hourly volume fractions. The minimum value is set to 0.8 if recorded as zero. This correction of the minimum value is necessary to avoid division by zero. This reduces the possible excessive effect that slightly erroneous data close to the detection limit of modern ozone monitors would have on $R$. The first indicator, $P_{1}$, includes, as a correction factor to $R$, the average of the daily maximum values $M$ relative to the overall average $A$ in the period of interest. This quotient, $M / A$, normally has a value close to 2 . The second indicator, $P_{2}$, includes a more sophisticated correction for the total time when a chosen limiting value (we used $80 \mathrm{ppb}$ ) has been exceeded. This correction factor was arbitrarily adjusted so as to make the value of $P_{2}$ double that of $R$ when the limiting value was exceeded on average once per week (168 is the number of hours per week). The third indicator, $P_{3}$, which is defined as the geometrical mean of the previous two indicators, therefore includes both corrections, and accounts for situations when $P_{1}$ and $P_{2}$ differ considerably.

$$
P_{3}=\sqrt{P_{1} \cdot P_{2}}
$$

Thus, we have chosen $P_{3}$ as the principal PP indicator for our recent analyses ${ }^{9,10,11}$ including the present one.

The three indicators should have a greater value when $R$ is high. Since $R$ reflects the difference between the daily maximum and minimum, and indirectly the daily ozone turnover, these indicators may also be a valid measure for adverse effects on living organisms and materials.

Maximum-to-minimum ratios depend, of course, on both the high and low values measured. The low values, close to zero, are likely to have a strong effect on the average ratio and consequently on the indicator values that are based on this ratio. This is also easily seen from the frequency distribution of the measured values.

\section{RESULTS AND DISCUSSION}

The results for the growth season (April through September) for all the stations are shown in Table 2.

From Table 2, we can see that for all stations, the contributions of indicators $P_{1}$ and $P_{2}$ to $P_{3}$ are similar; the values of $P_{1}$ and $P_{2}$ do not differ much for any given station. Thus, one may conclude that the influences of the average daily maxima $(M)$, total ozone averages $(A)$ and excess time $\left(t_{\mathrm{exc}}\right)$ values are quite similar. Indeed, higher maxima values are associated with excess time values but altogether the number of hours above the threshold of $80 \mathrm{ppb}$ is quite low. For indicator $P_{3}$, Table 2 shows a significant improvement at nearly all the stations after the year 2000 .

Four of the eleven urban stations are in London: Marylebone and Bloomsbury, located slightly west of city centre, are $2 \mathrm{~km}$ apart and the other two, Hillingdon, $20 \mathrm{~km}$ to the west and Teddington, $20 \mathrm{~km}$ to the SWW are $12 \mathrm{~km}$ apart. The Bloomsbury station has been recording data since 1993, Hillingdon and Teddington since 1997 and the Marylebone records are from 1999 onwards (1998 is incomplete). A graph of $P_{3}$ values over the years for these stations shows a strong correlation between the two pairs and indicates that in the years 1999 and 2003 all the stations recorded higher levels of PP.

All three Scottish stations have low indicator values. Note, however, that there is no data from urban stations in Scotland. 


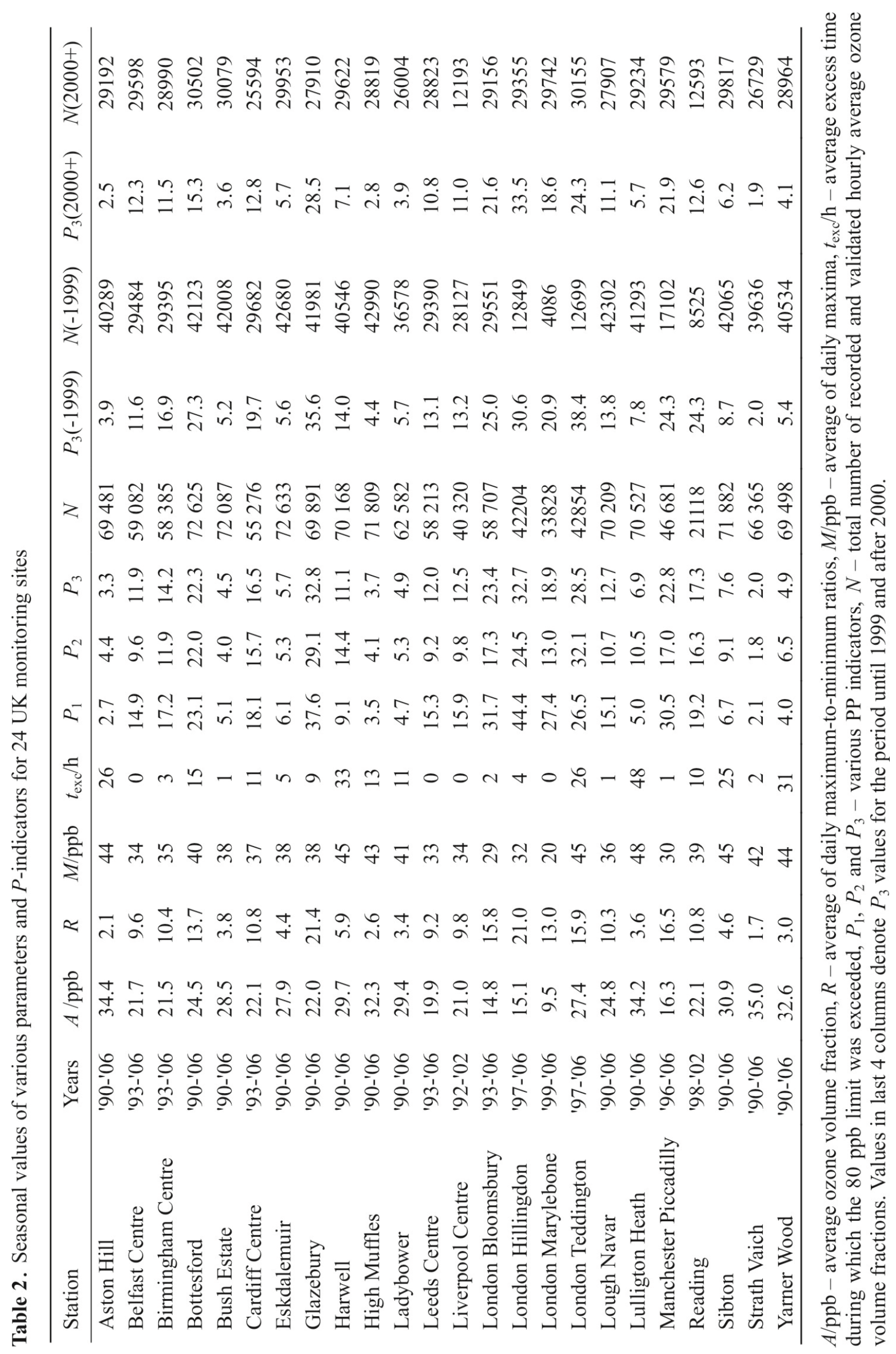

Croat. Chem. Acta 86 (2013) 57. 


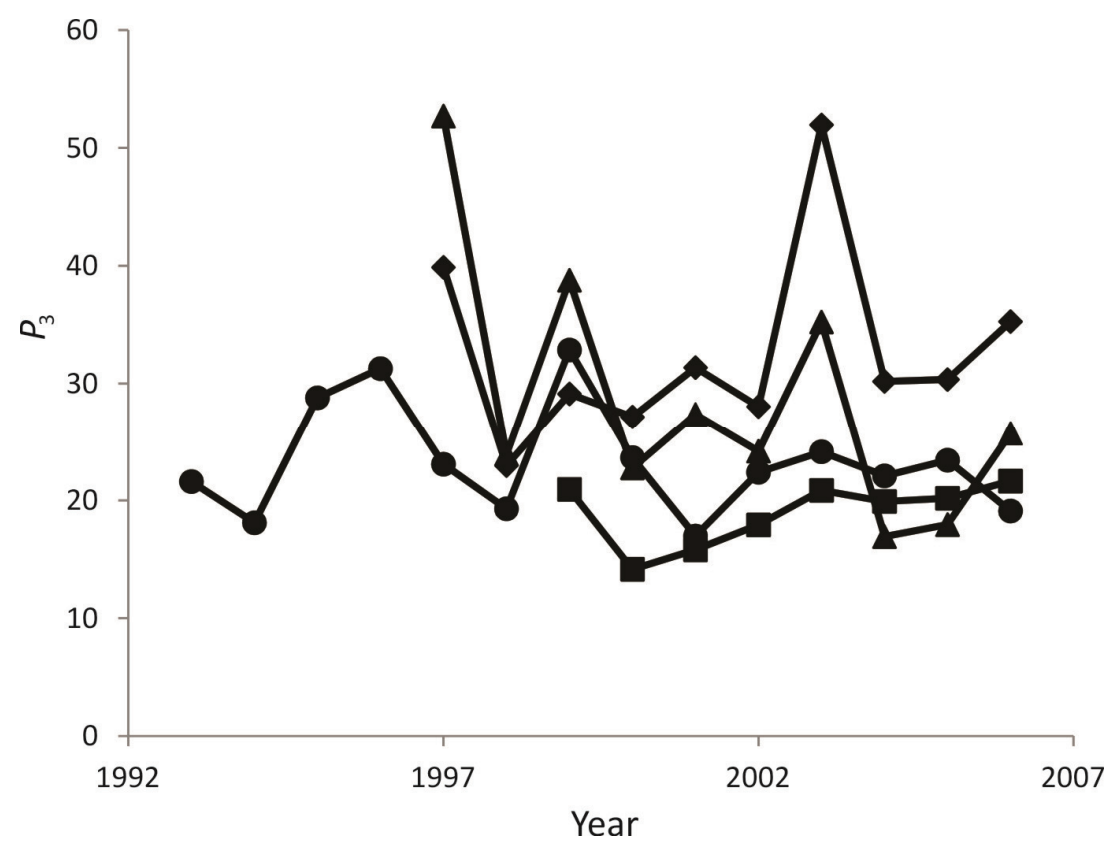

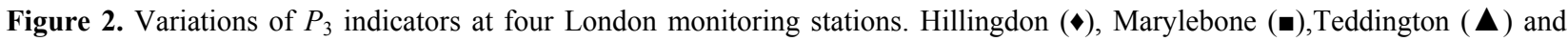
Bloomsbury $(\bullet)$.

Both Northern Irish stations, Belfast and Lough Navar, have similar indicator values around 10, although one is urban and the other rural.

The English and Welsh stations show lower values for the rural stations than for the urban ones. Rural stations Bottesford and Glazebury, as well as possibly Harwell have elevated indicator values similar to those of the nearby urban stations.

Generally, one can observe that all three indicators show high values at urban stations during the growth season. Most rural stations show lower values of all three indicators, the notable exception being Glazebury, which shows the second highest values of all stations. The fact that Glazebury is located in the vicinity of two major English cities, Manchester and Liverpool, and is affected by their industrial emissions may explain this observation. Indeed, it has already been shown for Glazebury and Bottesford stations, that their whole-year data, similar to those of urban stations, can be explained by their location near big cities. ${ }^{7}$ During the growth season, London (Hillingdon and Teddington, ahead of Bloomsbury) has the highest indicator values of all the urban stations, followed by Manchester Piccadilly, Cardiff, Liverpool, Birmingham, Leeds, and Belfast. A significant decrease in these values after the year 2000 is observed at nearly all the stations when compared with the years prior to 2000 (Table 2). This decrease, as shown also by Jenkin, would have been even more pronounced if the year 2003 had not been so exceptional. ${ }^{12}$ As reported earlier, ${ }^{6}$ sites with indicator values below 10 should be classified as "clean," with $10-40$ as "medi- um" and sites with values above 100 as "polluted." Thus, all rural sites Bottesford, Glazeburry, Harwell and Lough Navar would be classified as medium PP (the last two probably only up to 2003).

All covered stations at altitudes above $200 \mathrm{~m}$ have very low indicator values, in agreement with the findings for continental stations ${ }^{6,13}$ that elevated sites show lower indicator values. Note that in the British Isles, the definition of "elevated" is different than in continental Europe where only sites above $800 \mathrm{~m}$ are considered as elevated.

The frequency distributions of ozone volume fractions at the different sites can be represented by histograms of a box-width of 5 ppb (Fig. 3). For sites with low $P_{3}$ values, the distributions show a normal (Gaussian) shape whereas for sites with high $P_{3}$ values, the distributions differ drastically from the normal, showing a much higher frequency of low ozone volume fractions. The same can be said for the cumulative probability distribution, which generally follows a sigmoidal curve that spreads out as the $P_{3}$ indicator increases. This is to be expected since the indicators are largely determined by the average daily maximum-to-minimum ratio, $R$, which is necessarily higher the larger the spread of the measured values is. The indicator values become high with the number of very low hourly averages as observed for Glazebury, London and Manchester-Piccadilly stations. None of the stations show substantial excess time. In fact, only three stations (Yarner Wood, Lullington Heath and Harwell) show on average slightly more than one hour of excess time per week 


\begin{tabular}{|c|c|c|}
\hline $\begin{array}{l}\mathrm{SV}\left(P_{3}=2.0\right) \\
=\end{array}$ & $\frac{\vdots}{\mathrm{LH}\left(P_{3}=6.9\right)}$ & $\begin{array}{l}\mathrm{BI}\left(P_{3}=14.2\right) \\
\vdots \\
\vdots\end{array}$ \\
\hline 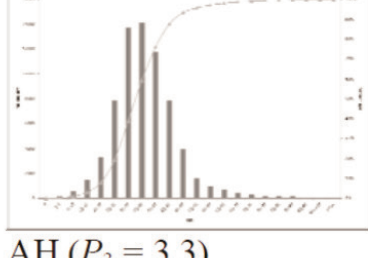 & 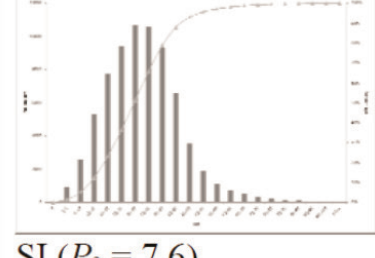 & $\begin{array}{l}\vdots \\
\vdots \\
\vdots\end{array}||||_{\mid, \ldots}$ \\
\hline $\mathrm{AH}\left(P_{3}=3.3\right)$ & $\mathrm{SI}\left(P_{3}=7.6\right)$ & $\mathrm{CA}\left(P_{3}=16.5\right)$ \\
\hline 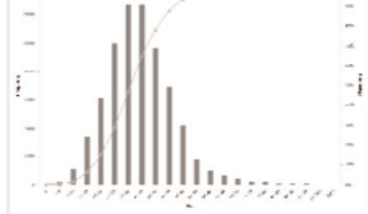 & $\therefore$ & 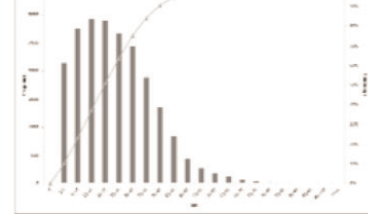 \\
\hline $\mathrm{HM}\left(P_{3}=3.7\right)$ & $\mathrm{HW}\left(P_{3}=11.1\right)$ & $\operatorname{RE}\left(P_{3}=17.3\right)$ \\
\hline$=$ & $-\|\mid\| \|_{1}$ & $\overline{-}-\left.1||||||\right|_{1, \ldots}$ \\
\hline $\mathrm{BU}\left(P_{3}=4.5\right)$ & $\mathrm{BE}\left(P_{3}=11.9\right)$ & $\mathrm{BO}\left(P_{3}=22.3\right)$ \\
\hline 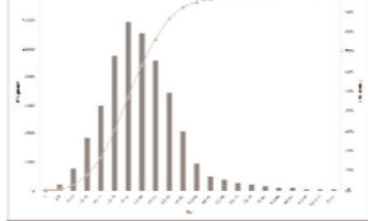 & 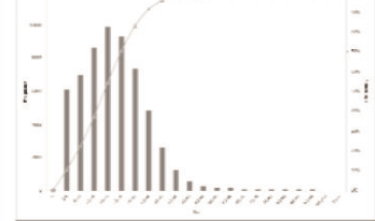 & $-\left.||||\right|_{\left.\right|_{1}}$ \\
\hline $\mathrm{YW}\left(P_{3}=4.9\right)$ & $\mathrm{LE}\left(P_{3}=12.0\right)$ & $\mathrm{MA}\left(P_{3}=22.8\right)$ \\
\hline-1\|\|$_{\left.\right|_{1, \ldots}}$ & $=|l| \mid \|_{1}$ & $=\left.|| l||\right|_{\left.\right|_{1, \ldots}, \ldots}=$ \\
\hline $\mathrm{LB}\left(P_{3}=4.9\right)$ & $\mathrm{LI}\left(P_{3}=12.5\right)$ & $\mathrm{LO}\left(P_{3}=23.4\right)$ \\
\hline$=1|\||||_{1, \ldots}$ & $-\left.||||||\right|_{1 . \ldots}$ & 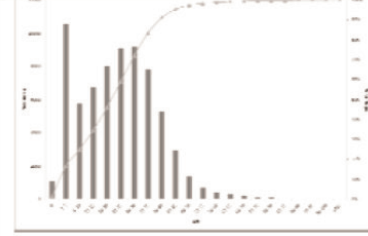 \\
\hline $\mathrm{ES}\left(P_{3}=5.7\right)$ & $\mathrm{LN}\left(P_{3}=12.7\right)$ & $\mathrm{GL}\left(P_{3}=32.8\right)$ \\
\hline
\end{tabular}

Figure 3. Histogram representations of frequency distributions of ambient ozone fractions (in 5 ppb intervals). Station abbreviations are shown in Table 1.

leading to relatively small corrections of $R$. The other potentially high contributor to the indicator values, the average of the daily maxima, $M$, is also considerably low, being highest (48 ppb) at Lullington Heath. However, the average $A$ for the investigated periods of growth seasons correlates quite nicely $\left(r^{2}=0.97\right)$ with 
the sum of the ozone frequency intensities for data between 0 and $20 \mathrm{ppb}$.

If we compare the indicator values for stations covered in this report with those for some other regions during the early $2000 \mathrm{~s}$, for example, those in central Europe ${ }^{6}$ Croatia, Italy and Slovenia, ${ }^{13}$ where $P_{3}$ is generally higher than 40 at urban sites (with the exception of Osijek and Rijeka where industries shrunk in the early 1990s), we conclude that the PP indicator values for the UK sites are lower than those of central and southern Europe and show a tendency of becoming even lower in future. Production of ozone in Mediterranean area is dominated by huge photochemical production of ozone in this area due to larger number of sunny days which is combined with hemispheric-scale spring maximum. $^{14,15}$ Even more, fair weather conditions favour transport of the air masses throughout the whole Mediterranean region ${ }^{16}$ and further north in the central Europe. ${ }^{17}$ Situation in the UK is somewhat different then in Mediterranean area where transport between sites highly influences the ozone levels. ${ }^{18}$ In comparison with an earlier obsrevations, ${ }^{6}$ we can, nevertheless, see the clear difference between urban and rural sites, but this transport can be the cause for lower $P_{3}$ values in the urban stations in comparison with the rest of Europe since the maximum levels of hourly ozone volume fractions noticed in this period are not very high. This can also be seen in a Table 2 as a low $t_{\text {exc }}$. Still, indicator values are higher for urban sites despite the "urban decrement" of daily maxima compared with those for rural sites, which further promotes the idea of PP indicators which correctly point to the cities as the main pollution generators.

The major advantage of the proposed PP indicators $P_{1}, P_{2}$ and $P_{3}$ is the using of easily measured ozone concentrations to monitor overall photochemical pollution caused by any pollutant monitored or omitted (for whatever reason) that may influence the ozone concentration. They are also in line with the fact that most air quality recommendations are based on the ozone volume fractions. Their advantage is also their simplicity which is one of the major requests for the indicators to be accepted. Various other indices for ozone are in use or proposed today; AOTx - accumulated ozone exposure over a threshold, MPOC - maximum permissible ozone concentration, ${ }^{19}$ W95 and W126 - sum of the weighted hourly concentrations in the observed period ${ }^{20}$ and SOMO35 - sum of excess of daily maximum $8 \mathrm{~h}$ means over the threshold of $35 \mathrm{ppb}$ in a year, ${ }^{21}$ just to mention some of them. First two indices are primarily used to calculate negative impact of ozone on the health of living organisms, i.e. vegetation.

W95 and W126 are two indicators that each hourly measured concentration weights with a function that provide greater emphasis to the values above 80 ppb (W95) and $100 \mathrm{ppb}$ (W126). Those two indicators, basically, show much greater differences between polluted and unpolluted areas than simple hourly averaged ozone concentration.

Exposure parameter SOMO35, i.e. sum of excess of daily maximum 8-hour means over the threshold of $35 \mathrm{ppb}$ in a year is based on assumption that the level of $35 \mathrm{ppb}$ as daily maximum 8-hour mean ozone concentration should not have any effects. For days with ozone concentration above $35 \mathrm{ppb}$ as maximum 8-hour mean, only the increment exceeding $35 \mathrm{ppb}$ is used to calculate effects. All other data are excluded from this index. Authors claim that this indicator is based on the application of a very conservative approach to integrated assessment modelling. This index reflects the seasonal cycle, geographical distribution of background ozone concentrations and range of concentrations for which models provided reliable estimates. It is also argued that SOMO35 is highly influenced by meteorological conditions which, therefore, must be taken into account.

\section{CONCLUSION}

Surprisingly, almost all the cities exhibit lower ozone averages (less than $22 \mathrm{ppb}$ ), daily maxima averages (less than $37 \mathrm{ppb}$ ) and excess times (from zero to two hours per week on average) than the rural areas. Since ozone is the main (in fact usually the only monitored) contributor to reduced air quality during the growth season, one would conclude that, based on direct threshold values, rural sites are more polluted than urban ones. Although this finding may be explained from the chemical point of view, we feel that the explanation may be unsatisfactory from the viewpoint of air quality assessment. The chemistry of surface ozone formation in polluted air is a very complex reaction system where ozone, its precursors and numerous pollutants react to form a range of reactive and hazardous intermediates, products and organic aerosols. Thus, in polluted air, we would expect a lower daylight maximum but higher ozone turnover and a greater decrease in ozone volume ratio after ozone formation ends at night. That complex mixture, in which ozone is still the most abundant but not necessarily the most hazardous component, is what we call here photochemical pollution and the ratio of daily maximum-to-minimum ozone volume fraction could, with some care (cum grano salis), be used as a parameter for assessment of its levels. At sites with high local sources of nitric oxide and/or unsaturated hydrocarbons as well as at sites exposed to strong atmospheric transport this picture can be blurred. The latter aspect was recently investigated ${ }^{22}$ by correlation between ozone concentration and the routes of air masses during ozone episodes. Nevertheless, appropriate use of the proposed indicators could provide a tool for identification of sites prone to pollution and for taking adequate 
measures to prevent photochemical pollution and photosmog episodes. A rationale for the link between the solely on ozone data based $R$ and anthropogenic pollution effects yields its strong correlation with the sum of average ozone and $\mathrm{NO}_{2}$ volume fractions $\left(r^{2}>\right.$ 0.9; available $\mathrm{NO}_{2}$ data for BE, BI, CA, LB, LE, LO and $\mathrm{LH}$ stations were 26.5, 29.3, 26.3, 6.9, 37.0, 53.6 and 6.6 , respectively).

Acknowledgements. We thank the UK Automatic Urban and Rural Network (AURN) of the UK Department for Environment, Food and Rural Affairs (DEFRA) for making the validated monitoring data freely available via the National Air Quality Information Archive. This work has been financially supported by the Ministry of Science, Education and Sports of the Republic of Croatia (Project code 098-0982915-2947). The authors would like to thank Enago (www.enago.com) for the English language review. The authors are grateful to Dr. S. Madronich (UCAR, Boulder,CO) for the suggestion to correlate $R$ with the average sum of ozone and $\mathrm{NO}_{2}$ data.

\section{REFERENCES}

1. E. Paoletti, Environ. Pollut. 157 (2009) 1397-1398.

2. D. S. Stevenson, F. J. Dentener, M. G. Schultz, K. Ellingsen, T. P. C. van Noije, O. Wild, G. Zeng, M. Amann, C. S. Atherton, N. Bell, D. J. Bergmann, I. Bey, T. Butler, J. Cofala, W. J. Collins, R. G. Derwent, R. M. Doherty, J. Drevet, H. J. Eskes, A. M. Fiore, M. Gauss, D. A. Hauglustaine, L. W. Horowitz, I. S. A. Isaaksen, M. C. Krol, J.-F. Lamarque, M. G. Lawrence, V. Montanaro, J.-F. Müller, G. Pitari, M. J. Prather, J. A. Pyle, S. Rast, J. M. Rodriguez, M. G. Sanderson, N. H. Savage, D. T. Shindell, S. E. Strahan, K. Sudo, and S. Szopa, J. Geophys. Res. - Atmos. 111(2006) D08301.

3. J. Giles, Nature 7 (2005) 435.

4. ICP, Manual on methodologies and criteria for modelling and mapping critical loads \& levels and air pollution effects, risks and trends. ICP Mapping and Modelling, UNECE CLRTAP, 2004. (Accessed 13 July 2012)

5. E. Paoletti, A. de Marco, and S. Racalbuto, Environ. Monit. Assess. 128 (2007) 19-30.

6. E. Kovač-Andrić, G. Šorgo, N. Kezele, T. Cvitaš, and L. Klasinc, Environ. Monit. Assess. 165 (2010) 577-583.

7. M. E. Jenkin, Atmos. Environ. 42 (2008) 5434-5445.

8. J. L. Jimenez, M. R. Canagaratna, N. M. Donahue, A. S. H. Prevot, Q. Zhang, J. H. Kroll, P. F. de Carlo, J. D. Allan, H. Coe, N. L. Ng, A. C. Aiken, K. S. Docherty, I. M. Ulbrich, A. P.
Grieshop, A. L. Robinson, J. Duplissy, J. D. Smith, K. R. Wilson, V. A. Lanz, C. Hueglin, Y. L. Sun, J. Tian, A. Laaksonen, T. Raatikainen, J. Rautiainen, P. Vaattovaara, M. Ehn, M. Kulmala, J. M. Tomlinson, D. R. Collins, M. J. Cubison, E. J. Dunlea, J. A. Huffman, T. B. Onasch, M. R. Alfarra, P. I. Williams, K. Bower, Y. Kondo, J. Schneider, F. Drewnick, S. Borrmann, S. Weimer, K. Demerjian, D. Salcedo, L. Cottrell, R. Griffin, A. Takami, T. Miyoshi, S. Hatakeyama, A. Shimono, J. Y. Sun, Y. M. Zhang, K. Džepina, J. R. Kimmel, D. Sueper, J. T. Jayne, S. C. Herndon, A. M. Trimborn, L. R. Williams, E. C. Wood, A. M. Middlebrook, C. E. Kolb, U. Baltensperger, and D. R. Worsnop, Science 326 (2009) 1525-1529.

9. L. Klasinc, T. Cvitaš, S. P. McGlynn, M. Hu, X. Tang, and Y. Zhang, Croat. Chem. Acta 84 (2011) 11-16.

10. T. Cvitaš, L. Klasinc, B. Matasović, and S. P. McGlynn, Int. J. Chem. Model. 4 (2012)

11. B. Matasović, T. Cvitaš, and L. Klasinc, Croat. Chem. Acta $\mathbf{8 5}$ (2012) 71-76.

12. A. Alebić-Juretić, T. Cvitaš, N. Kezele, L. Klasinc, G. Pehnec, and G. Šorgo, Bull. Environ. Contam. Toxicol. 79 (2007) 468471.

13. L. Klasinc, T. Cvitaš, A. de Marco, N. Kezele, E. Paoletti, and M. Pompe, Fresen. Environ. Bull. 19 (9B) (2010) 1982-1988.

14. P. Pochanart, H. Akimoto, S. Maksyutov, and J. Staehelin, Atmos. Environ. 35 (2001) 5553-5566.

15. J. Lelieveld, H. Berresheim, S. Borrmann, P. J. Crutzen, F. J. Dentener, H. Fischer, J. Feichter, P. J. Flatau, J. Heland, R. Holzinger, R. Kormann, M. B. Lawrence, Z. Levin, K. Markowicz, N. Mihalopoulos, A. Minikin, V. Ramanthan, M. de Reus, G. J. Roelofs, H. A. Scheeren, J. Sciare, H. Schlager, M. Schulz, P. Siegmund, B. Steil, E. G. Stephnaou, P. Stier, M. Traub, C. Warneke, J. Williams, and H. Ziereis, Science 298 (2002) 794-799.

16. G. Kouvarakis, M. Vrekoussis, N. Mihalopoulos, K. Kourtidis, B. Rappenglueck, E. Gerasopoulos, and C. Zerefos, J. Geophys. Res. 107 (D18) (2002) 8137.

17. S. Henne, M. Furger, and A. S. H. Prévôt, J. Appl. Meteorol. 44 (2005) 620-633.

18. AQEG, Ozone in the United Kingdom, DEFRA, 2009. (Accessed 7 December 2012)

19. L. Grünhage, G. H. M. Krause, B. Köllner, J. Bender, H.-J. Weigel, and H.-J. Jäger, Environ. Pollut. 111 (2001) 355-362.

20. A. S. Lefohn, J. A. Laurence, and R. J. Kohut, Atmos. Environ. 22 (1988) 1229-1240.

21. M. Amann, I. Bertok, J. Cofala, F. Gyarfas, C. Heyes, Z. Klimont, W. Schöpp, and W. Winiwarter, Baseline scenarios for the Clean Air for Europe Programme. Final report, Laxenburg IIASA, 2005.

22. K.-H. Tseng, J.-L. Wang, M.-T. Cheng, and B.-J. Tsuang, Aerosol Air. Qual. Res. 9 (2) (2009) 149-171. 